\title{
PROGESTERONE IN THE CORPUS LUTEUM AND PLACENTA OF THE ARMADILLO, DASYPUS NOVEMCINCTUS
}

\author{
ANANT P. LABHSETWAR AND ALLEN C. ENDERS \\ Department of Anatomy, Washington University School of Medicine, \\ St. Louis, Missouri, U.S.A.
}

(Received 3rd August 1967)

Summary. The progesterone content of corpora lutea from armadillos in the delayed implantation period and both corpora and placentae from animals in the post-implantation period was determined chemically.

During the delay period the weight of the corpus luteum, but not the total progesterone content ( $\mu \mathrm{g} /$ gland), was significantly higher in animals carrying blastocysts than animals without blastocysts. Following implantation of the blastocyst, the size as well as the total progesterone content increased significantly $(P<0 \cdot 05)$. However, during the latter part of the post-implantation period ( $>6 \mathrm{~cm}$ crown-rump length) both the size and the progesterone content decreased by more than two-fold $(P<0 \cdot 05)$. However, at this stage considerable amounts of progesterone were found in placentae and in one uterine vein blood sample studied. In contrast, no hormone could be detected in the placenta of earlier stages (i.e. $<5 \mathrm{~cm}$ crown-rump length).

These data suggest that the functional activity of the corpus luteum may be lower during delayed implantation than in the early postimplantation period. However, during the latter part of gestation the corpus luteum regresses, and it is probable that at this stage the placenta contributes significant amounts of progesterone.

\section{INTRODUCTION}

The reproductive cycle of the nine-banded armadillo (Dasypus novemcinctus) is characterized by a distinct period of delayed implantation of 3 to 5 months duration (see Enders, 1966, for a recent review). The length of the postimplantation period has been estimated to be $4 \frac{1}{2}$ months. The four genetically identical young born develop from a single blastocyst. Only the ovary from which the single ovum was ovulated contains a corpus luteum. There are no accessory corpora lutea. Removal of both ovaries, but not either one, during the delay period precipitates implantation of the blastocyst (Buchanan, Enders \& Talmage, 1956; Enders \& Buchanan, 1959; Enders, 1966). The endocrine factors underlying delayed and post-ovariectomy implantations in the armadillo are unknown. 
The corpora lutea appear active during both the delayed and immediate post-implantation periods on the basis of histologic examination or bio-assay of peripheral plasma by Hooker-Forbes test (Enders, 1966; Talmage, Buchanan, Kraintz, Lazo-Wasem \& Zarrow, 1954). However, during the latter part of gestation the corpora lutea show morphological signs of degeneration (Enders, 1966).

In the present study, the progesterone content of the corpora lutea, placentae, adrenal glands and peripheral and uterine vein blood from armadillos in different reproductive states was measured by chemical methods.

\section{MATERIALS AND METHODS}

Female armadillos were captured from the wild population in east Texas between October 1965 and March 1967, and shipped by the dealer to the laboratory within a week of captivity; further details may be found elsewhere (Enders, 1966). The tissues (corpora lutea, placentae, adrenals, peripheral and uterine vein blood) were collected either at laparotomy or at autopsy within 2 to 3 weeks of arrival of the animals and were stored at $-20^{\circ} \mathrm{C}$ until analysis.

\section{Steroid determination}

Initially sixteen corpora lutea and four placentae were collected. To each sample $\left[4-{ }^{14} \mathrm{C}\right]$ progesterone (approximately 8000 counts $/ \mathrm{min} ; 36 \cdot 1 \mu \mathrm{c} / \mathrm{mm}$ ) was added, and the tissue was homogenized in $95 \%$ ethanol. The supernatant was decanted and filtered. The residue was extracted four more times with additional solvent and similarly filtered. The pooled filtrate was analysed for progesterone by the procedure of Zander (1962). Each sample was quantitated by its u.v. absorption at $240 \mathrm{~m} \mu$ and the Allen correction was applied to measurements taken at 220,240 and $260 \mathrm{~m} \mu$ for the absorption of non-specific impurities. The mean recovery of added tracer was $47 \pm 7 \%$. The relatively lower recovery was principally due to the increased numbers of times the placental samples had to be rechromatographed.

For the remaining samples, a much simpler procedure was employed: the luteal, placental and adrenal tissues were homogenized in distilled water to obtain a 5 to $10 \%$ homogenate. Subsequently, the tracer (approximately 24,000 counts/min) was added to these samples (as well as the plasma samples), and the sample was thoroughly mixed with 3 to 5 volumes of ethyl acetate: ether mixture $(3: 1, \mathrm{v} / \mathrm{v})$. The organic phase was separated by centrifugation. The procedure was repeated three to four times with additional solvent. The pooled organic phase which contained over $92 \%$ of the added tracer was dried under vacuum or in nitrogen. The luteal samples were then applied to thinlayer chromatography plates (Kieselgel containing u.v. indicator, $250 \mu$ thick). The plates were developed in toluene:ethyl acetate $(1: 1, \mathrm{v} / \mathrm{v})$ mixture for about $2 \mathrm{hr}$. The other tissue samples were first defatted by storing overnight at $-20^{\circ} \mathrm{C}$. in $70 \%$ methanol and then applied to TLC plates. The zones corresponding in $R_{F}$ value to authentic progesterone were localized under u.v. and eluted with optically pure methanol. A few samples of corpora and all samples of other tissues required rechromatography, which was done either in 
the same solvent system or cyclo-hexane:ethyl acetate $(5: 2, \mathrm{v} / \mathrm{v})$ mixture. Before each spectrophotometric measurement portions of each sample were saved for counting radio-activity in a Packard Tricarb liquid scintillation spectrometer (Model 314). The mean recovery rates of added tracer in luteal and placental tissues were $74 \pm 5 \%$ and $54 \pm 3 \%$ respectively. The results that follow have been corrected for procedural losses.

\section{Acetylation}

Certain samples of corpora lutea and all placentae analysed with the procedure of Zander initially failed to yield a peak u.v. absorption at $240 \mathrm{~m} \mu$. These samples were then acetylated by treatment with three drops each of acetic anhydride and pyridine at room temperature, and rechromatographed $18 \mathrm{hr}$ later in the hexane-65\% methanol system. The steroid spot on each chromatogram was localized by using an automatic radiochromatogram scanner (Vanguard No. 880) and by u.v. contact photography. In all instances a clear absorption peak at $240 \mathrm{~m} \mu$ was obtained from steroid in the sample after removal of the contaminating substances by acetylation.

\section{0 $\beta$-hydroxypregn-4-en-3-one reaction}

For further identification of the isolated steroid, samples were pooled in three groups (delay corpora lutea, corpora lutea from animals in which implantation had already occurred and placentae) and treated with $20 \beta$ hydroxy-steroid dehydrogenase enzyme as described by Henning \& Zander (1962). Rechromatography and localization of the steroid spot were done as described under acetylation.

\section{Isolation of progesterone}

\section{RESULTS}

The mobility in hexane- $65 \%$ methanol system and u.v. absorption maxima of the isolated steroid were similar to those of an authentic sample of progesterone. Upon acetylation, the $R_{F}$ value as well as the location of the radio-active peak remained unchanged. The latter coincided with the u.v. spot of the isolated steroid. Following incubation with $20 \beta$-hydroxy-steroid dehydrogenase and rechromatography, the $R_{F}$ value of the isolated steroid was indistinguishable from that of an authentic sample of $20 \beta$-dihydroprogesterone run on the adjoining strip. The radio-active peak also shifted in location to correspond to the u.v. spot of $20 \beta$-dihydroprogesterone. From these results it is apparent that the steroid isolated was progesterone.

After initial chromatography of each sample and before acetylation, each chromatogram was scanned for possible u.v. absorbing spots corresponding to authentic samples of the $20 \alpha$ and $\beta$-dihydroprogesterones. None could be detected. Although no further tests were applied to seek these steroids, it was assumed that the concentration of these compounds, if present, was relatively low.

\section{Corpus luteum}

In the delay period, corpora lutea of animals carrying blastocysts were significantly heavier $(P<0.05$, Text-fig. 1$)$ than those from animals without 
blastocysts. However, progesterone content ( $\mu$ g/gland) was not significantly different between these two groups, possibly because the number of observations (four) in the delay animals without blastocysts was limited. Following implantation of the blastocyst, both the weight and the total progesterone content $(\mu \mathrm{g} /$ gland) of corpora lutea increased significantly $(P<0 \cdot 05$, Text-fig. 1 ), and then decreased during the latter part of gestation (Text-fig. 1). The
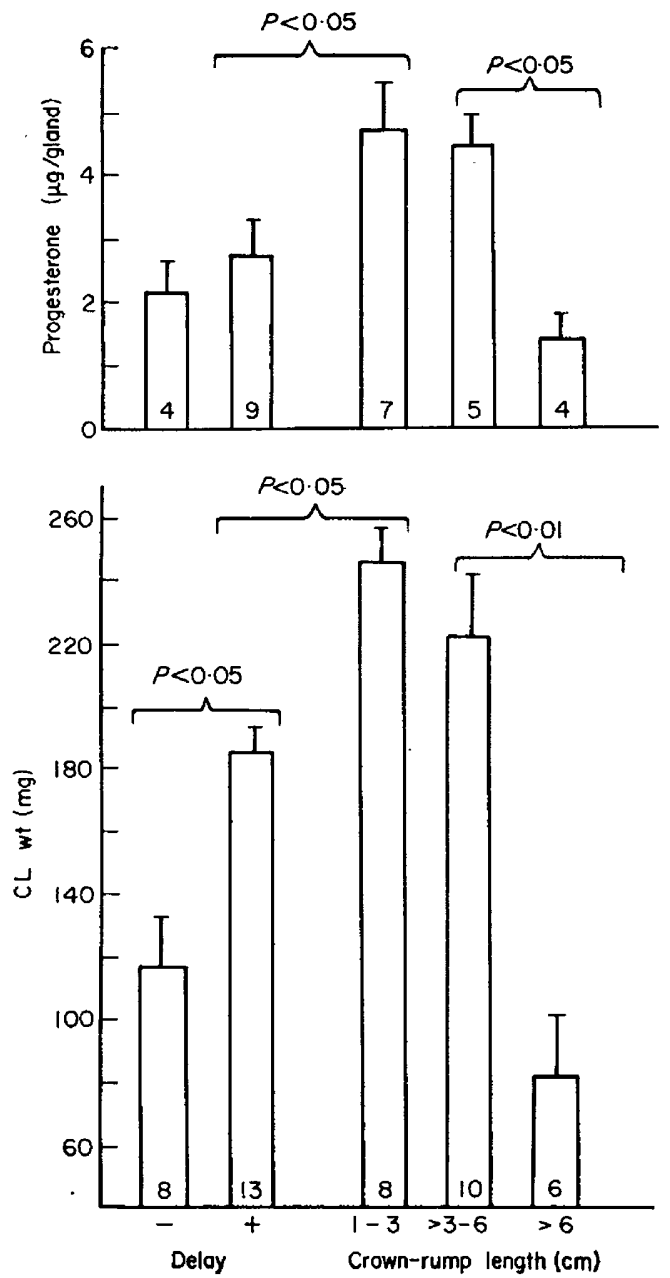

TExT-FIG. 1. Changes in the weight and progesterone content of corpora lutea during the delay period [armadillos with $(+)$ and without $(-)$ blastocysts] and during the postimplantation period (armadillos with foetuses). The number of glands studied is at the base of the column while the bar at the top denotes S.E. Significant comparisons are shown.

mean concentration of progesterone in the different groups ranged from 19 to $26 \mu \mathrm{g} / \mathrm{g}$, and no significant differences were present among any of the groups.

\section{Placenta}

The placental weight increased linearly with gestation age. For each centimetre increase in crown-rump length of the foetus, the placental weight 
increased by $0.33 \mathrm{~g}$ (Text-fig. 2). No progesterone could be detected in the placenta until the foetuses had reached a crown-rump length of over $4 \mathrm{~cm}$ (Text-fig. 2). After this stage, there was a progressive increase in the total progesterone content $(\mu \mathrm{g} /$ placenta). The concentration of progesterone $(\mu \mathrm{g} / \mathrm{g})$ followed the same trend. There was a tendency for a lower progesterone content $(\mu \mathrm{g} / \mathrm{placenta})$ as well as concentration $(\mu \mathrm{g} / \mathrm{g})$ in two near-term placentae (Text-fig. 2).

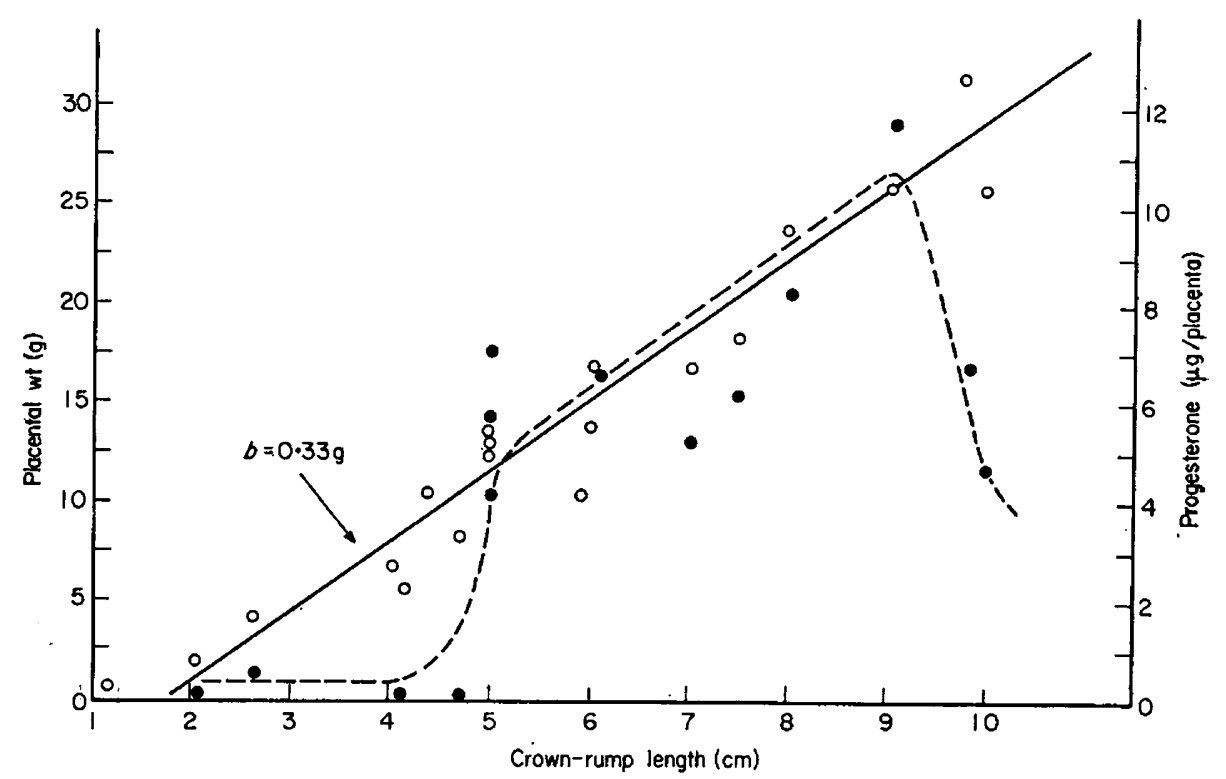

TEXT-FIG. 2. Changes in the weight $(O)$ and progesterone content (..$-\bullet)$ of placentae during the post-implantation period in the armadillo.

\section{Plasma}

A total of eight samples of peripheral plasma, ranging in volume from 32 to $50 \mathrm{ml}$ (two from delay animals and six from post-implanted animals carrying 2- to 7-cm embryos) was analysed, but no progesterone could be detected in any of them, suggesting that the concentration in pregnancy was less than 0.2 to $0.5 \mu \mathrm{g} / 100 \mathrm{ml}$ plasma, which is the sensitivity of the method employed. Of the two uterine vein blood samples $(20 \mathrm{ml}$ each), the one from the animal carrying $4 \cdot 3-\mathrm{cm}$ embryos (placental wt $10 \cdot 7 \mathrm{~g}$ ) contained $23 \mu \mathrm{g}$ progesterone/ $100 \mathrm{ml}$ of blood, while in the sample from an animal carrying embryos of less than I $\mathrm{cm}$ (placental wt $158 \mathrm{mg}$ ) no progesterone could be detected.

\section{Adrenals}

A total of eleven adrenal glands (four from non-ovulated and seven from delayed animals) was analysed; only three glands from each group contained any detectable progesterone $(4.9 \mu \mathrm{g} / \mathrm{g}$ in non-ovulated, compared with $6.6 \mu \mathrm{g}$ in delay, $P>0.05)$. However, recovery of the progesterone added to the adrenal gland samples was very poor (about $32 \%$ ). 
'Post-delayed' corpora lutea

Implanted embryos are never found in the armadillo from late June to September except under experimental conditions (Hamlett, 1932; Enders, 1966). Therefore, blastocysts still unimplanted in the uterus at any time between mid-February and May must be destined to eventual degeneration. Such animals may be designated 'post-delay' animals. Four such animals killed in February and March were found to carry 'abnormal' looking blastocysts. The weight of the corpora in this group $(106 \pm 12 \mathrm{mg})$ was significantly smaller $(P<0.05)$ than that in delay animals with blastocysts killed between November and January $(183 \pm 13 \mathrm{mg})$, but the progesterone content was similar $(2.67$ and $2 \cdot 70 \mu \mathrm{g} / \mathrm{gland})$ in the two groups.

\section{DISCUSSION}

Studies on the functional status of the armadillo corpus luteum during the delay period have been somewhat equivocal. Hamlett (1935) thought that the corpus luteum was non-functional during the delay period, judging from the histology of this gland and the relative lack of progestational changes in the uterus. On the other hand, Talmage et al. (1954), on the basis of Hooker-Forbes assay of peripheral plasma, and Enders $(1962,1966)$, on the basis of luteal morphology as revealed by light and electron microscopy, considered the corpus luteum of delay to be functional. The presence of progesterone in detectable quantities in these corpora adds further support to this conclusion. Progesterone has also been detected in the corpora of delayed implantation in the European badger (Canivenc, 1966) and roe deer (Short \& Hay, 1966).

Both the size and the total progesterone content of the corpora lutea of delay were significantly lower than those of immediate post-implantation period. The extent to which these two parameters reflect the functional activity of the corpora in this species is unknown, although in several other species some correlation has been found (Short, 1964). It seems likely that the lower weight and progesterone content of delay corpora are indications that these glands are functioning at a lower level during the delay period than during the immediate post-implantation period. Whether such a deficiency in progesterone may be the cause of delayed implantation in this species is unknown, but injection of progesterone in delay animals, with or without ovaries, has not been found to result in the implantation of blastocysts (Enders, 1966).

The size as well as the progesterone content of the corpora was found to decrease markedly during the latter part of gestation. Morphologically, these glands show pronounced degeneration (Enders, 1966). These observations taken together indicate that functional activity of the armadillo corpus luteum declines during the latter part of gestation. At this stage, however, increasing quantities of progesterone can be detected in the placenta. In fact, the progesterone level in the armadillo placenta appears to be one of the highest among several species that have been studied. [It is higher than the values reported for the mare (Short, 1961) and monkey (Short \& Eckstein, 1961), and lower than the human placenta of mid-gestation (Zander, 1959).] A lack of detectable amounts of progesterone in as much as $125 \mathrm{ml}$ of peripheral blood even at late gestation 
indicates that the presence of blood in the placenta cannot account for the high level of hormone in this organ. The pronounced decreases in the size as well as the progesterone content of the corpora lutea at this stage make them an unlikely significant source of progesterone. Additionally, one sample of uterine vein blood studied was found to contain a high level of progesterone. These observations suggest that the placenta in this species forms an additional source of progesterone at least during the latter part of gestation.

\section{ACKNOWLEDGMENTS}

We are indebted to Dr Walter Wiest for valuable discussion about methodology and liberal supplies of $\alpha$ - and $\beta$-dihydroprogesterones; to Dr G. Mikhail for certain facilities during the initial phases of this work; and to Dr S. Clark for use of the liquid scintillation counter. This study was supported by U.S. National Science Foundation grant GB-2476, and by grant 5T1 HD-21 from the National Institute of Child Health and Human Development.

\section{REFERENCES}

Buchanan, G. D., Enders, A. C. \& TAlmage, R. V. (1956) Implantation in armadillos ovariectomized during the period of delayed implantation. F. Endocr. 14, 121.

Canivenc, R. (1966) A study of progestation in the European badger (Meles meles L.). In: Comparative Biology of Reproduction in Mammals, p. 15. Ed. I. W. Rowlands. Academic Press, London and New York.

Enders, A. C. (1962) Observations on the fine structure of lutein cells. F. Cell Biol. 12, 101.

ENDERs, A. C. (1966) The reproductive cycle of the nine-banded armadillo (Dasypus novemcinctus). In: Comparative Biology of Reproduction in Mammals, p. 295. Ed. I. W. Rowlands. Academic Press, London and New York.

Enders, A. C. \& Buchanan, G. D. (1959) Some effects of ovariectomy and injection of ovarian hormones in the armadillo. F. Endocr. 19, 251.

Hamlett, G. W. D. (1932) The reproductive cycle in the armadillo. Z. wiss. Zool. A, 141, 143.

Hamlett, G. W. D. (1935) Delayed implantation and discontinuous development in mammals. Q. Rev. Biol. 10, 432.

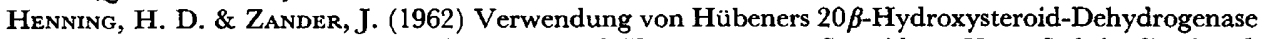
bei microchemischer Identifizierung und Trennung von Steroiden. Hoppe-Seyler's Z. physiol. Chem. 330, 31.

Short, R. V. (1961) Progesterone. In: Hormones in Blood, chap. 13, p. 279. Eds. G. H. Gray and A. L. Bacharach. Academic Press, London and New York.

SHorr, R. V. (1964) Ovarian steroid synthesis and secretion in vivo. Recent Prog. Horm. Res. 20, 303.

Short, R. V. \& Eckstein P. (1961) Oestrogen and progesterone levels in pregnant rhesus monkeys. 7. Endocr. 22, 15.

SHoRT, R. V. \& HAY, M. F. (1966) Delayed implantation in the roe deer, Capreolus capreolus. In: Comparative Biology of Reproduction in Mammals, p. 173. Ed. I. W. Rowlands. Academic Press, London and New York.

Talmage, R. V., Buchanan, G. D., Kraintz, F. W., Lazo-Wasem, E. A. \& Zarrow, M. X. (1954) The presence of a functional corpus luteum during delayed implantation in the armadillo. 7. Endocr. 11, 44.

Zander, J. (1959) Gestagens in human pregnancy. In: Recent Progress in Endocrinology of Reproduction, p. 255. Ed. C. W. Lloyd. Academic Press, London and New York.

Zander, J. (1962) Progesterone. In: Methods in Hormone Research, Vol. 1, p. 91. Ed. R. I. Dorfman. Academic Press, London and New York. 